\title{
DISTROFIA POLIMORFA POSTERIOR Y LASIK
}

\section{POSTERIOR POLYMORPHOUS DYSTROPHY AND LASIK}

\author{
HUERVA $\mathrm{V}^{1}$, MATEO AJ ${ }^{2}$
}

\section{RESUMEN}

Objetivo/Método: Mujer hipermétrope de 50 años desea información sobre cirugía refractiva. En la córnea se aprecia vesículas y bandas en la membrana de Descement y endotelio catalogándose de distrofia polimorfa posterior (DPP). El recuento endotelial resulta bajo por lo que se le contraindica cualquier cirugía refractiva corneal.

Resultados/Conclusiones: La presencia de vesículas y bandas a nivel de la membrana de Descement y endotelio es característico de una DPP. En estos casos resulta obligatorio realizar una microscopía especular previa a una cirugía refractiva con láser excimer. Un recuento de células endoteliales bajo puede constituir una contraindicación para el LASIK hipermetrópico en casos de DDP por el posible riesgo de descompensación endotelial.

Palabras clave: Distrofia polimorfa posterior, PPD, distrofias corneales posteriores, distrofia endotelial de Fuchs, LASIK, hipermetropía.

\section{ABSTRACT}

Objective/Method: A 50-year-old hyperopic woman requested information about refractive surgery. Vesicle and band lesions at Descemet's membrane and endothelium were suggestive of posterior polymorphous dystrophy (PPD). Lower than normal endothelial cell densities were detected. A corneal refractive procedure was not recommended in this case.

Results/Conclusions: The presence of vesicles and bands at Descemet's membrane and endothelium is suggestive of PPD. Specular microscopy is mandatory in such patients, although corneal decompensation is not evident. A low endothelial cell count may be a contraindication for a hyperopic LASIK procedure in cases of PPD because of the possible risk of corneal decompensation (Arch Soc Esp Oftalmol 2008; 83: 607-614).

Key words: Posterior Polymorphous Dystrophy, PPD, posterior corneal dystrophies, Fuchs corneal dystrophy, LASIK, hyperopia.

\section{INTRODUCCIÓN}

La Distrofia Polimorfa Posterior (DPP) constituye una de las distrofias corneales posteriores junto con la distrofia de Fuchs y la distrofia endotelial hereditaria congénita (CHED) $(1,2)$. Es una enfermedad hereditaria de carácter autosómico dominante $(1,2)$. Las lesiones características de la DPP afec- tan a la membrana de Descement y al endotelio presentando una gran variabilidad. Puede aparecer vesículas, lesiones en banda y opacidades difusas. Con menor frecuencia puede observarse edema corneal, sinequias anteriores periféricas y guttas endoteliales $(1,2)$. La mayor parte de estos pacientes son asintomáticos y se descubren al ser explorados por otro motivo. Rara vez requieren un queratoplastia

\footnotetext{
Recibido: 5/3/07. Aceptado: 2/9/08.

1 Doctor en Medicina. Hospital Universitario Arnau de Vilanova. Lérida.

2 Doctor en Medicina. Hospital Clínico Universitario Lozano Blesa. Zaragoza.

Correspondencia:

Valentín Huerva

C/. Río Ara, 20

22520 Fraga (Huesca)

España

E-mail: vhuerva@mixmail.com
} 
por descompensación corneal. Cuando se asocian a un defecto refractivo y solicitan un procedimiento quirúrgico para su corrección pueden plantear dudas a la hora de decidir su intervención. Las pérdidas endoteliales tras un procedimiento refractivo con láser excímer no suelen ser significativas (tabla I), sin embargo existen casos donde esta pérdida no es despreciable (tabla I). Solamente se han documentado dos casos de láser in situ queratomiulesis (LASIK) para correción de miopía en pacientes afectos de DPP (3). No existe documentación de la seguridad del LASIK para correción de hipermetropía en la DPP.

\section{CASO CLÍNICO}

Mujer de 50 años de edad sin antecedentes de interés ni enfermedades oculares conocidas que acude a visita por su defecto refractivo hipermetrópico. Está interesada en la cirugía refractiva de su defecto y solicita información acerca de esta posibilidad en su caso. El examen subjetivo de la refracción y agudeza visual fue el siguiente: ojo derecho (OD): $20^{\circ}-0,75+2,25=10 / 10$, ojo izquierdo (OI): $30^{\circ}-1,75+3=0,7$, necesitando adición de 2 dioptrías para visión cercana en ambos ojos. Bajo cicloplejía el defecto refractivo fue en OD: $20^{\circ}-0,50+2,50$ y en OI: $30^{\circ}-1,75+4$. La paciente no refería haber utilizado lentes de contacto con anterioridad. Los resultados de la topografía y paquimetría corneal se muestran en las figuras 1 y 2 . En el estudio biomicroscópico se objetivó la presencia de numerosas vesículas a nivel del endotelio así como imágenes en forma de banda más acusadas en ojo izquierdo
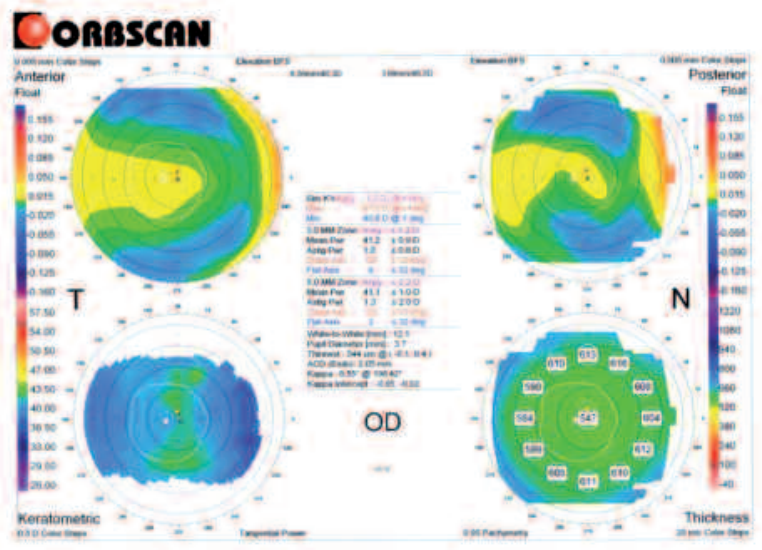

(fig. 3). La existencia de este polimorfismo a nivel posterior de la córnea fue sugerente de una DPP. La tensión ocular y el fondo de ojo fueron normales. Para decidir si podía ser sometida a una cirugía refractiva, se le practicó una microscopía especular de campo amplio del endotelio corneal valorando la densidad endotelial especialmente la periférica. Este estudio mostró la presencia de vesículas rodeadas de endotelio aparentemente normal, presencia de bandas acelulares y pobre celularidad en algunas zonas con riesgo de descompensación corneal (figs. 4 y 5). Estos hallazgos confirmaron la presencia de una DPP y se le desaconsejó cualquier procedimiento con finalidad refractiva en sus córneas.

\section{DISCUSIÓN}

La expresión clínica de la DPP varía considerablemente. Puede observarse desde lesiones endoteliales aisladas hasta la descompensación corneal, sinequias anteriores y glaucoma en miembros de la misma familia $(1,2,4)$. La enfermedad es bilateral pero asimétrica. En la gran mayoría de los casos es asintomática y se diagnóstica en una exploración rutinaria (1) como en el presente caso. La enfermedad suele aparecer entre la segunda y la tercera décadas. Se desarrolla a nivel endotelial y la membrana de Descement y puede dividirse en tres patrones: lesiones vesiculares, lesiones en banda y opacidades difusas (1). La lesión principal de la DPP son las vesículas las cuales ocurren en un $42 \%$ de forma aislada y en un $48 \%$ asociadas en combinación con bandas $(1,4)$. Solamente en un $10 \%$ se asocian a opacidades difusas $(1,4)$. Las vesículas se
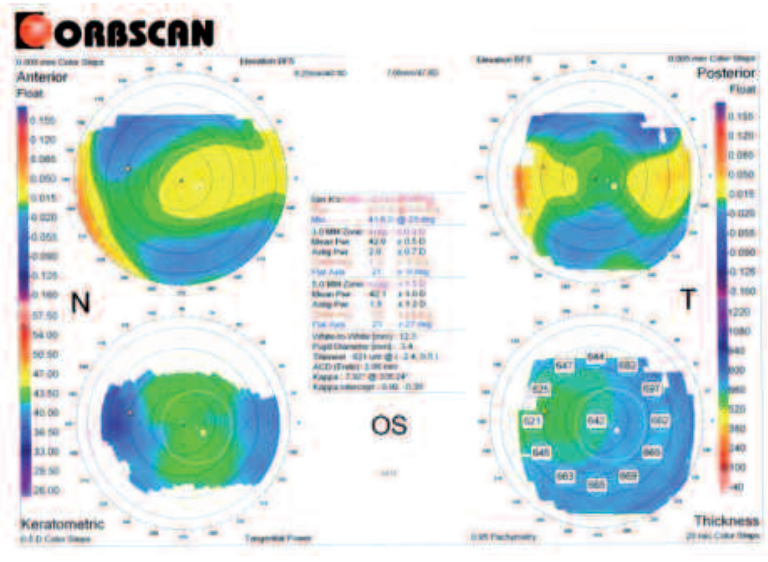

Fig. 1 y 2: Topografía corneal de ambos ojos de mediante Orbscan. 


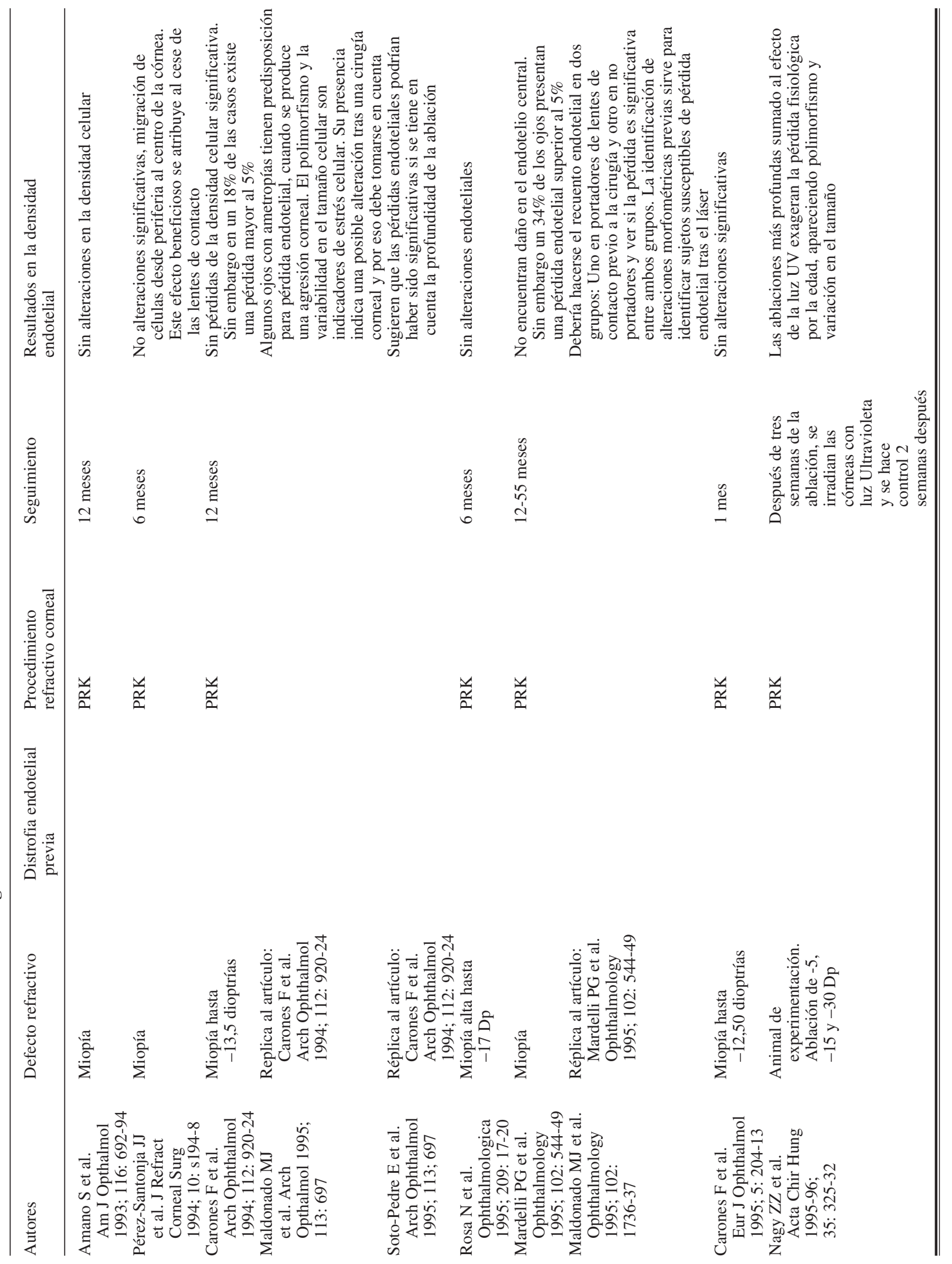




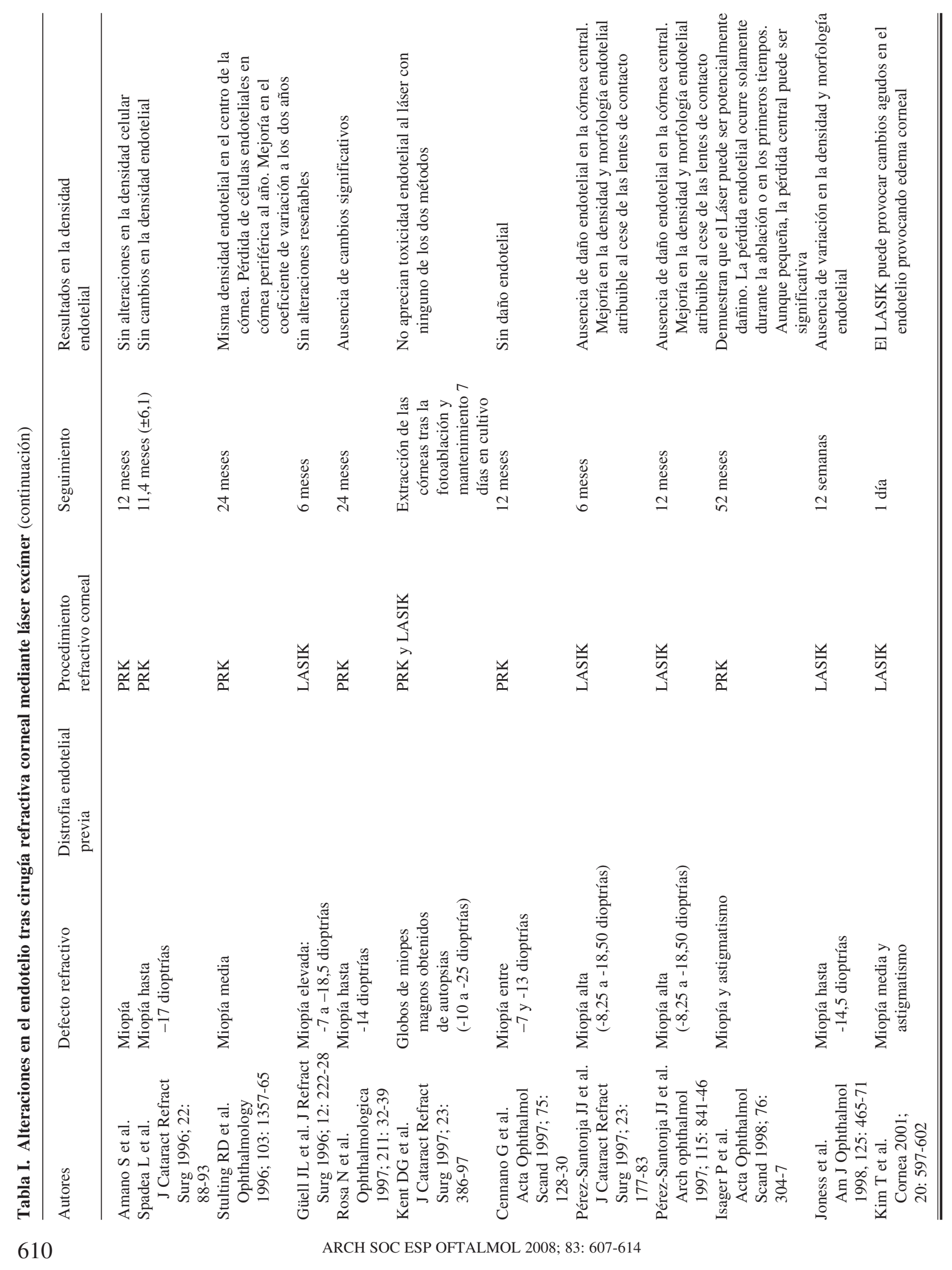




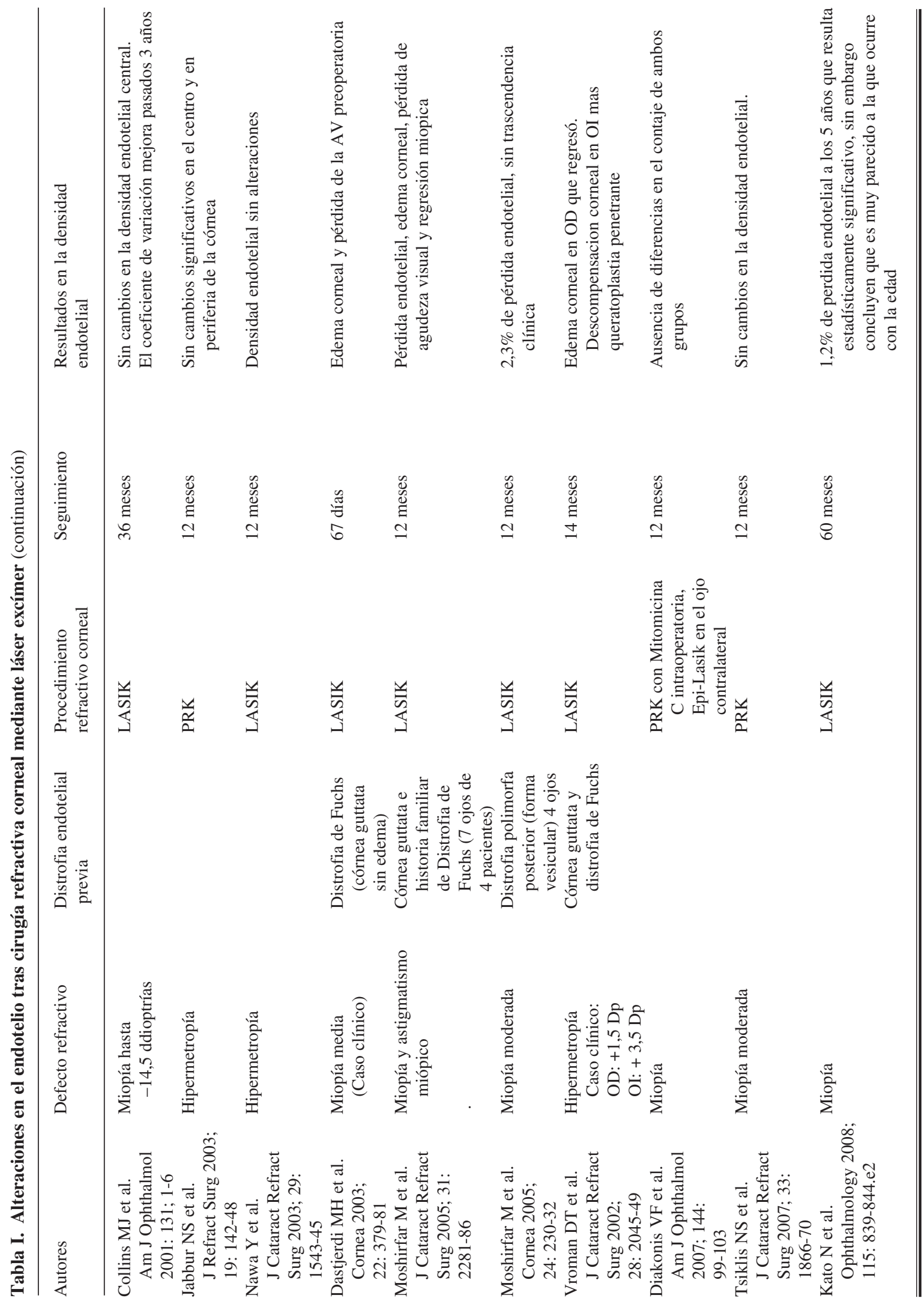




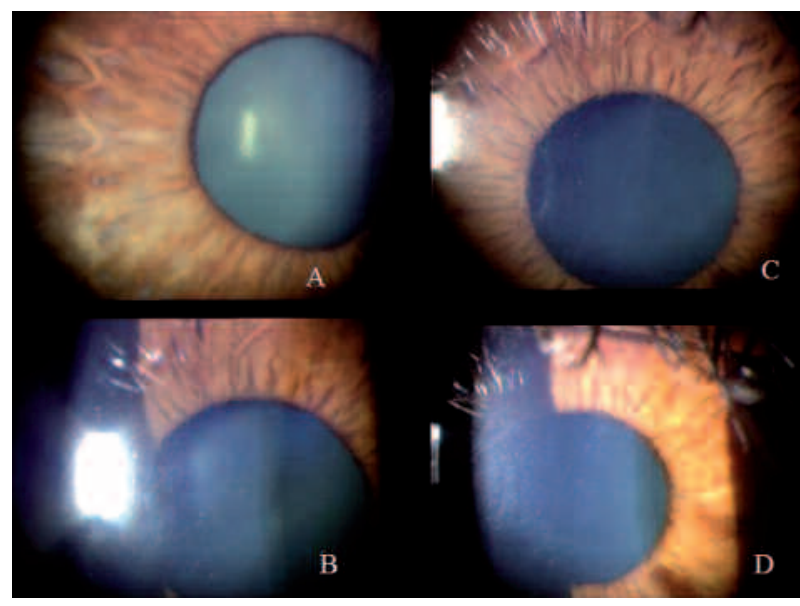

Fig. 3: Biomicroscopía. Abundantes vesículas a nivel de la descement y endotelio. Ojo derecho: Patrón en piel de naranja $(A, B)$. Ojo izquiero, presencia de vesículas formando bandas $(C D)$.

describen como lesiones vacuolares, nodulares, anulares, o en cráter, transparentes y rodeadas de un halo blanquecino o grisáceo $(1,2)$. Pueden adoptar diverso tamaño y encontrarse aisladas o en grupos, pudiendo confluir en forma de bandas $(1,2)$. No se disponen datos de la prevalencia de la enfermedad. El hecho de que la enfermedad sea asintomática sugiere que muchas de estas vesículas pueden pasar desapercibidas en un examen de rutina, pudiendo existir muchos casos no diagnosticados.

El diagnóstico de la entidad es biomicroscópico, confirmándose con los hallazgos de la microscopía especular de campo amplio. Las formas en banda

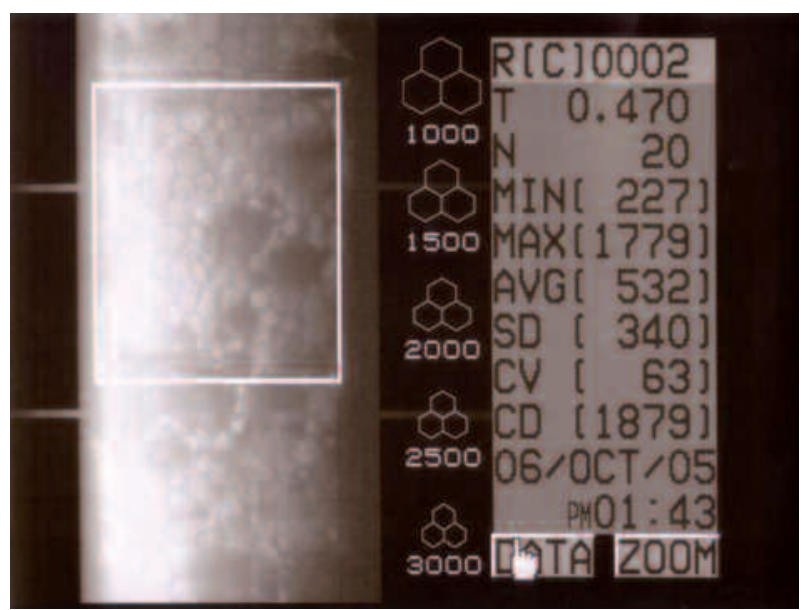

Fig. 4: Microscopía especular de campo amplio de zonas periféricas de la córnea. Vesículas o cráteres rodeados de células endoteliales sanas en ojo derecho.

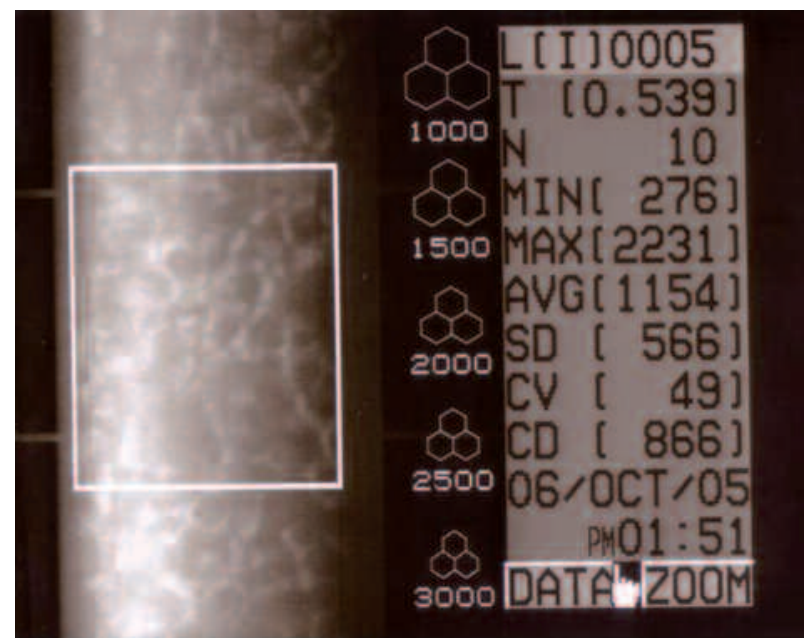

Fig. 5: Microscopía especular de campo amplio en ojo izquierdo. Pérdida difusa de células endoteliales.

son documentadas con menor frecuencia $(1,4)$. En el presente caso se estudia además la topografía de la superficie posterior de la córnea sin objetivarse cambios que se correspondan con las bandas visibles en la biomicroscopía. Los resultados topográficos y paquimétricos no contraindican la intervención para eliminar el astigmatismo e hipermetropía del presente caso. El recuento endotelial en la DPP suele ser más bajo que en sujetos normales, sin embargo se ha documentado que no existe una pérdida más acelerada de células endoteliales con la edad (4). Por lo tanto, solamente plantea problemas cuando se desea una cirugía refractiva corneal. En la mayoría de los estudios no se han encontrado pérdidas significativas de células endoteliales centrales después del LASIK en córneas sanas (tabla I). Cuando se ha realizado la técnica LASIK para corregir la hipermetropía en córneas con distrofia de Fuchs (5), la evolución ha sido hacia la descompensación corneal y queratoplastia. En el LASIK hipermetrópico, la ablación es periférica por lo que debe tenerse en cuenta la celularidad endotelial a este nivel (5). En los dos casos descritos de LASIK para corregir miopía en córneas con DPP (3), la pérdida endotelial al año ha sido del 2,3\%. Esta pérdida resulta significativa al compararla con la pérdida en sujetos sanos que suele ser del 0,5\% (3). Durante un año de seguimiento no se observó descompensación corneal (3), siendo de reseñar que el contaje endotelial previo a la cirugía fue mayor a 2.200 células $/ \mathrm{mm}^{2}$ en el primer caso y mayor a 2.600 células $/ \mathrm{mm}^{2}$ en el segundo. 
En nuestra opinión, teniendo en cuenta que las formas en banda y difusas de DPP tienen un contaje endotelial más bajo (4), el resultado del láser hipermetropíco en la distrofia de Fuchs (5), la posibilidad de perdida de un 2,3\% al año tras el LASIK (3) más la pérdida endotelial progresiva con la edad, desaconsejamos realizar una cirugía refractiva por gran riesgo de descompensación corneal en estos pacientes. Nuestra hipótesis no demostrada es que un contaje mínimo de 1.500 células $/ \mathrm{mm}^{2}$ en zonas periféricas sería lo mínimo imprescindible para realizarles un LASIK con seguridad. Entre $1.000 \mathrm{y}$ 2.000 células $/ \mathrm{mm}^{2}$ existe menos riesgo pero todavía son susceptibles de descompensación. Cualquier alteración endotelial que comprometa la bomba endotelial puede producir problemas de adherencia del disco corneal en el postoperatorio. Éste es otro motivo por el que desaconsejamos esta intervención en estos casos. Aunque sería evitable con un procedimiento de superficie como la PRK, no existe completa seguridad con respecto a la pérdida endotelial con posterioridad. La PRK alejaría la ablación del endotelio, sin embargo se le somete a una sobrecarga funcional por hidratación estromal vía epitelio denudado y por mayor penetración y exposición a componentes algo tóxicos de los colirios. Algunos estudios no refieren pérdidas significativas de células endoteliales a los seis meses de haber realizado una PRK, mientras otros muestran una pérdida endotelial muy significativa cuando el recuento endotelial se realiza a los 50 meses (tabla I). Según estos datos, en nuestra opinión, también debe desaconsejarse estos procedimientos en pacientes afectos de una DPP.

En conclusión se documenta un nuevo caso de DPP diagnosticado casualmente al realizar una exploración rutinaria. La presencia de vesículas a nivel de la membrana de Descement y endotelio debe hacer pensar en la presencia de una DPP. Aunque la córnea esté transparente y no se observen signos de edema corneal focal o difuso resulta obligatorio en estos casos un estudio de microscopia especular previo a la indicación de una cirugía refractiva con láser excímer.

\section{BIBLIOGRAFÍA}

1. Weisenthal RW, Streeten BW. Posterior membrane dystrophies. In: Krachmer JH, Mannis MJ, Holland EJ. Cornea. Philadelphia: Elsevier Mosby; 2005; I: 929-954.

2. Barraquer RI, de Toledo MC, Torres E. Distrofias y degeneraciones corneales atlas y texto. Barcelona: Expaxs; 2004; 222-234.

3. Moshirfar M, Barsam CA, Tanner MC. Laser in situ keratomileusis in patients with posterior polymorphous dystrophy. Cornea 2005; 24: 230-232.

4. Laganowsky HC, Sherrard ES, Kerr Muir MG. The posterior corneal surface in posterior polymorphous dystrophy: a specular microscopical study. Cornea 1991; 10: 224232.

5. Vroman DT, Solomon KD, Holzer MP, Peng Q, Apple DJ, Bowie EM. Endothelial decompensation after laser in situ keratomileusis. J Cataract Refract Surg 2002; 28: 2045 2049. 